\title{
TOWARDS A SELF-EXTENDING PARSER
}

\author{
Jaime G. Carbonell \\ Department of Computer Science \\ Carnegie-Mellon University \\ Pittsburgh, PA 15213
}

\begin{abstract}
This paper discusses an approach to incremental learning in natural language processing. The technique of projecting and Integrating semantic constraints to learn word definitions is analyzed as implemented in the POLITICS system. Extensions and improvements of this technique are developed. The problem of generallzing existing word meanings and understanding metaphorical uses of words is addressed in terms of semantic constraint integration.
\end{abstract}

\section{Introduction}

Natural language analysis, llke most other subfields of Artiflcial Intelligence and Computational Lingulstics, suffers from the fact that computer systems are unable to automatically better themselves. Automated learning is considered a very difficult problem, especially when applied to natural language understanding. Consequently, little effort has been focused on this problem. Some ploneering work in Artificial Intelligence, such as AM [1] and Winston's learning system [2] strove to learn or discover concept descriptions in well-defined domains. Although their efforts produced interesting idess and techniques, these techniques do not fully extend to a domain as complex as natural language analysis.

Rather than attempting the formidable task of creating a language learning system, I will discuss techniques for incrementally increasing the abillties of a flexible language analyzer. There are many tasks that can be consldered "Incremental language learning". Initially the learning domain is restricted to learning the meaning of new words and generalizing existing word definitions. There are number of A.l. techniques, and combinations of these techniques capable of exhibiting incremental learning behavior. I first discuss FOULUP and POLITICS, two programs that exhlbit a IImited capability for Incremental word learning. Secondly, the technique of semantic constraint projection and integration, as Implemented in POLITICS, is analyzed in some detall. Finally, I discuss the appllcation of some general learning techniques to the problem of generalizing word definitions and understanding metaphors.

\section{Learning From Script Expectations}

Learning word definitions in semantically-rich contexts is perhaps one of the simpler tasks of incremental learning. Initially I confine my discussion to situations where the meaning of a word can be learned from the immedlately surrounding context. Later I relax this criterion to see how global context and multiple examples can halp to learn the meaning of unknown words.

The FOULUP program [3] learned the meaning of some unknown words in the context of applying a script to understand a story. Scripts $[4,5]$ are trame-llke knowledge representations abstracting the important features and causal structure of mundane events. Scripts have general expectations of the actions and objects that will be encountered in processing a story. For Instance, the restaurant script expects to see menus, waitresses, and customers ordering and eating food (at different pre-specifled times in the story).

Foulup took advantage of these script expectations to conclude that Items referenced in the story, which were part of expected actions, were indeed names of objects that the script expected to see. These expectations were used to form definitions of new words. For instance, FOULUP induced the meaning of "Rebbit" in, "A Rabbit veered off the road and struck a tree," to be a self-propelled vehicie. The system used information about the automobile accldent script to match the unknown word with the script-role "VEHICLE", because the script knows that the only objects that veep off roads to smash into road-side obstructions are self propelled vehicles.

\section{Constraint Projoction in POLITICS}

The pOLITICS system $[6,7]$ induces the meanings of unknown words by a one-pass syntactlc and semantic constraint projection followed by conceptual enrtchment from planning and world-knowledge inferences. Consider how POLITICS proceeds when it encounters the unknown word "MPLA" in analyzing the sentence:

"Russia sent massive arms shipments to the MPLA in Angola."

Since "MPLA" follows the article "the" it must be a noun. adjective or adverb. After the word "MPLA", the preposition "In" is encountered, thus terminating the current prepositional phrase begun with "to". Hence, since all well-formed prepositional phrases require a head noun, and the "to" phrase has no other noun, "MPLA" must be the head noun. Thus, by projecting the syntactic constraints necessary for the sentence to be well formed, one learns the syntactic category of an unknown word. It is not always possible to narrow the categorization of a word to a single syntactic category from one example. In such cases, I propose intersecting the sets of possible syntactlc categories from more than one sample use of the unknown word untll the intersection has a single element.

POLITICS learns the meaning of the unknown word by a similar, but substantially more complex, application of the same principle of projecting constraints from other parts of the sentence and subsequently integrating these constraints to construct a meaning representation. In the example 
above, POLITICS analyzes the verb "to send" as either an ATRANS or a PTRAHS. (Schank [8] discusses the Conceptual Dependency case frames. Briefly. a PTRANS is a physical transfer of location, and an ATAANS is an abstract transfer of ownership, possession of control.) The reason why pOLITICS cannot decide on the type of TRANSfer is that it does not know whether the destination of the transfer (1.e., the MPLA) is a location or an agent. Physical objects, such as weapons, are PTRANSed to locations but ATRANSed to agents. The conceptual analysis of the sentence, with MPLA as yet unresolved, is dlagrammed below:

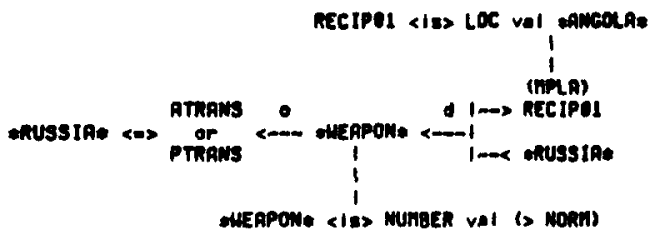

What has the analyzer learned about "MPLA" as a result of formulating the CD case frame? Clearly the MPLA can only be an actor (1.e., a person, an institution or a political entity in the POLITICS domain) of a location. Anything else would violate the constraints for the recipient case in both ATRANS and PTRANS. Furthermore, the analyzer knows that the location of the MPLA is Inside Angola. This Item of information is integrated with the case constraints to form a partial definition of "MPLA". Unfortunately both locations and actors can be located inside countries; thus, the identity of the MPLA is still not unlquely resolved. POLJTICS asalgns the name RECIPO to the partial definition of "MPLA" and proceeds to apply its inference rules to understand the political implicetions of the event. Here I discuse only the inferences relevant for further specifying the meaning of "MPLA".

\section{Uncertain Inference in Leaming}

POLITICS is a goal-driven inferencer. It must explain all actions in terms of the goels of the actors and reciplents. The emphasis on inducing the goals of actors and relating their actions to means of achieving these goals is integral to the theory of subjective understending embodied in POLITICS. (See [7] for a detalled discussion.) Thus, POLITICS tries to determine how the action of sending weapons can be pelated to the goals of the Soviet Union or any other possible actors involved in the situation. POLITICS knows that Angola was in a state of civil war; that is, a state where political factions were =xercising their goals of taking milltary and, therefore, polltical control of a country. Since possessing weapons is a precondition to military actions, POLITICS infera that the reclpient of the weapons may have been one of the political ractions. (Weapons are a means to fulfilling the goal of a political faction, therefore poLITICS is able to explain why the faction wants to receive weapons.) Thus, MPLA la inferred to be a political faction. This inference is integrated with the existing partlal definition and found to be consistent. Finally, the original action is refined to be an ATRANS, co transfer of possession of the weapons (not merely their location) helpa the political faction to achleve Its milltary goal.

Next, POLITICs tries to determine how sending weapons to a milltary faction can further the goals of the Soviet Union. Communist countries have the goal of spreading thetr Ideology. POLITICS concludes that this goal can be fulfilled only if the government of Angola becomes communist. Milltary ald to a political faction has the standard goal of milltary takeover of the government. Putting these two facts together, POLITICS concludes that the Russian goal can be fulfilled if the MPLA, which may become the new Angolan government, is Communist. The definition formed for MPLA is as follows:

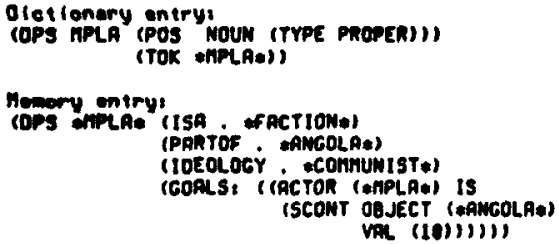

The reason why memory entries are distinct from dlctionary definitions is that there is no one-to-one mapping between the two. For instance. "Russta" and "Soviet Union" are two separate dictionary entries that refer to the same concept in memory. Similarly, the concept of SCONT (social or political control) abstracts information useful for the goal-driven inferences, but has no corresponding entry in the lexicon, as I found no example where such concept was expllcitly mentioned in newspaper headines of political conflicts (I.e., POLITICS' domain).

Some of the inferences that POLITICS made are much more prone to error than others. More speciflcally, the syntectic constraint projections and the CD case-frame projections are quite certain, but the goal-driven interences are only reasonable guesses. For instance, the MPLA could have been - plateau where Russia deposited Its weapons for later dellvery.

\section{A Strategy for Dealing with Uncertainty}

Given such possibilities for error, two possible strategies to deal with the problem of uncertain inference come to mind. First, the system could be restricted to making only the more certain constraint projection and integration inferences. This does not usually produce a complete definttion, but the process may be Iterated for other exemplars where the unknown word is used in different semantic contexts. Each time the new word is encountered, the semantic constraints are integrated with the previous partlal definition until a complete definition is formulated. The problem with this process is that it may require substantial number of iterations to converge upon a meaning representation, and when it eventually does, this representation will not be as rich as the representation resulting from the less certain goal-driven inferences. For instance, it would be impossible to conclude that the MPLA was Communist and wanted to take over Angole only by projecting semantic constraints.

The second method ls besed on the system's ability to recover from inaccurate inferences. This is the method 1 implemented in Politics. The first step requires the detection of contradictions between the inferred information and now incoming information. The next step is to asaign 
blame to the appropriate culprit, l.e., the inference rule that asserted the incorrect conclusion. Subsequently, the system must delete the inaccurate assertion and later inferences that depended upon It. (See [9] for a model of truth maintenance.) The final step is to use the new information to correct the memory entry. The optimal system within my paradigm would use a comblnation of both strategies - It would use its maximal inference capability, recover when inconsistencies arise, and iterate over many exemplars to refine and confirm the meaning of the new word. The first two criteria are present in the POLITICS implementation, but the system stops building a new definition after processing a single exemplar unless it detects a contradiction.

Let us brlefly trace through an example where POI.ITICS ls told that the MPLA is indeed a plateau after it inferred the meaning to be a political faction.

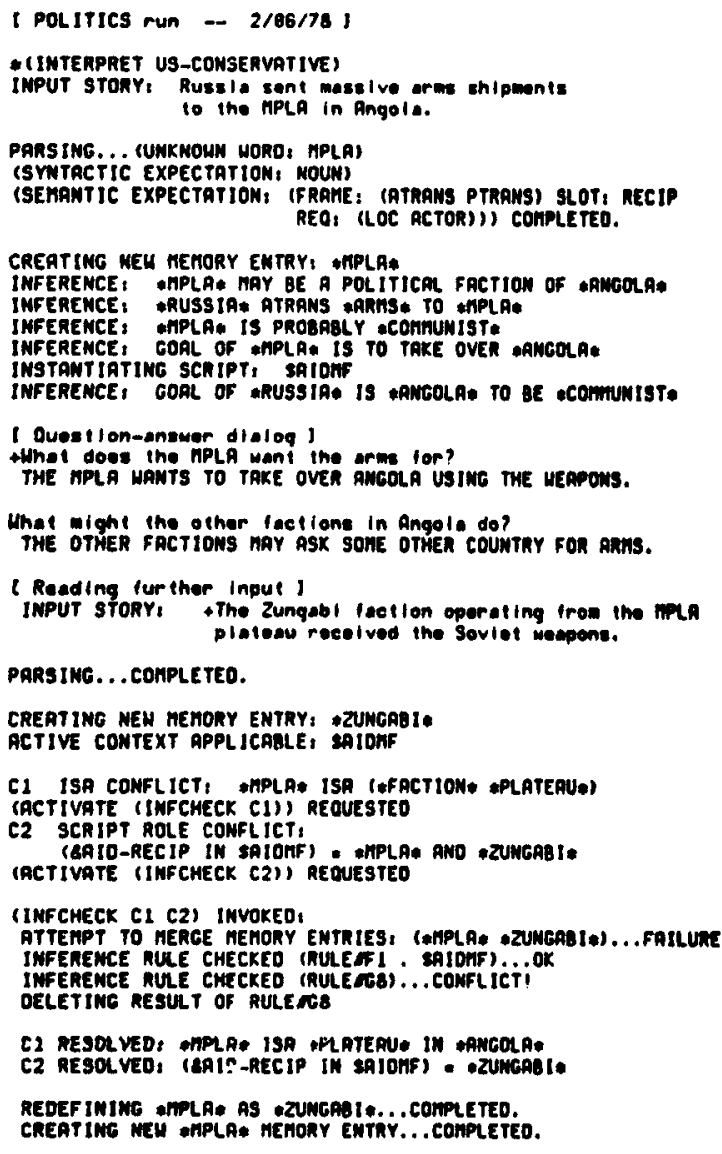

POLITICS realizes that there is an inconsistency in its interpretation when it tries to integrate "the MPLA plateau" with its previous definition of "MPLA". Political factions and plateaus are different conceptual classes. Furthermore, the new input states that the Zungabi pecelved the weapons, not the MPLA. Assuming that the Input its correct, POLITICs searches for an Inference rule to assign blame for the present contradiction. This is done simply by temporarlly deleting the result of each inference rule that was actlvated In the original interpretation untll the contradiction no longer exiats. The rule that concluded that the MPLA was a political faction is found to resolve both contradictions if doleted.
Since recipients of military aid must be political entitles, the MPLA being a geographical location no longer qualifies as a military aid reciplent.

Finally, POLITICS must check whether the inference rules that depended upon the result of the deleted rule are no longer applicable. Rules, such as the one that concluded that the polltical faction was communist, depended upon there being a political faction receiving military ald from Russia. The Zungabi now fulfil's this role; therefore, the inferences about the MPLA are transfered to the Zungabl, and the MPLA is redefined to be a plateau. (Note: the word "Zungabi" was constructed for this example. The MPLA is the present rulling body of Angola.)

\section{Extending the Projoct and Integrate Mothod}

The POLITICS implementation of the project-and-integrate technique is by no means complete. POLITICS can only induce the meaning of concrete or proper nouns when there is sufficient contextual information in a single exempler. Furthermore, POLITICS assumes that each unknown word will have only one meaning. In general it is useful to realize when a word is used to mean something other than its definition, and subsequently formulate an alternative definition.

I lllustrate the case where many examples are required to narrow down the meaning of a word with the following example: "Johnny told Mary that if she didn't give him the toy, he would (unknown-word) her." One can Induce that the unknown word is a verb, but its meaning can only be guessed at, in general terms, to be something unfavorable to Mary. For Instance, the unknown word could mean "take the object from", or "cause injury to". One needs more than one example of the unknown word used to mean the same thing in different contexts. Then one has a much richer, combined context from which the meaning can be projected with greater precision.

Figure 1 diagrams the general project-and-integrate algorithm. This extended version of POLITICS' word-learning technique addresses the problems of iterating over many examples, multiple word definitions, and does not restrict its Input to certain classes of nouns.

\section{Genorallzing Word Definitions.}

Words can have many senses, some more o"neral than others. Let us look at the problem of gen iizing the semantic definition of a word. Consider the case where "barrier" is deflned to be a physical object that dlsenables a transfer of location. (e.g. "The barrler on the roed to blocking my way.") Now, let us interpret the sentence, "Import quotas form a barrler to international trade." Clearly, an import quota is not a physical object. Thus, one can minimally generallze "barrier" to mean "anything that disenables a physical tranafer of location."

Let us substitute "tariff" for "quota" in our example. This suggests that our meaning for "barrier" la Insufficiently general. A tariff cannot disenable physical transfer: tariffs disenable willingness to buy or sell goods. Thus, one can further generallze the meaning of berriep to bes "anything that dieenables any type of transfer". Yet, some traee of the 
Flgure li The preject-and-Integrele wothed lor Indueing now word and concept dellinttlone

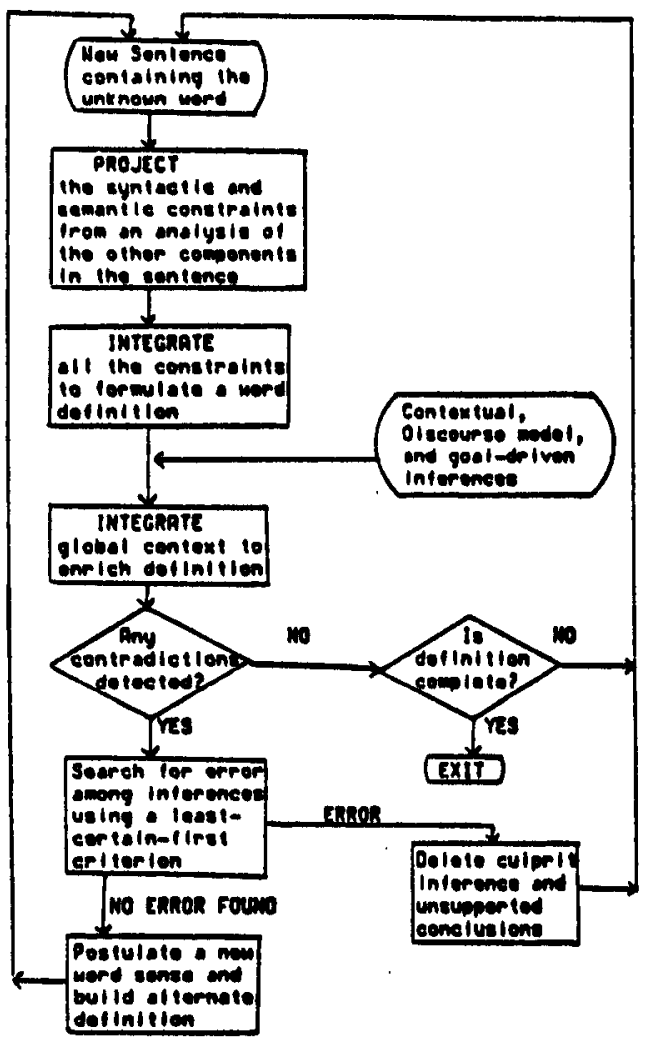

generallzation process must be remembered because the original meaning is often preferred, or metephorteally peferenced. Consider: "The trade barriers were llfted." and "The now legislation bulldozed existing trade berrlers." These sentences can only be understood motaphorleally. That is, one needs to refer to the original meaning of "barrier" as a physlcal object, in order for "lifting" or 'bulldozing" to make sense. After understanding the literal reaning of a "bulldozed barrier", the next step is to Infer he consequence of such an action, namely, the barrter no snger exists. Finally, one can pefer to the generallzed leaning of "barrler" to interpret the proposition that "The ow legialation caused the trade berriers to be no longer in xistence."

propose the esllowing rules to generalize word dafinitions id understand metaphorical references to their original, Imel definition:

1) If the definition of a word violates the semantic constraints projected from an interpretation of the rest of the sentence, create a now word-sense definition that copies the old definition minimally relaxing (1.e., generallzing) the violated conatraint.

2) In Interpreting new sentences always prefor the most specific definition if applicable.

3) If the generalized definition is encountered again In interpreting text, make it part of the permanent dictionary.
4)
a
definition requires further

generalization, choose the existing most general dofinition and minimally relax its violated semantic constraints untll a now, yet more general definition is formed.

5) If the case frame formulated in intepreting a sentence projects more specifle sementic constraints onto the word meaning than those condstent with the entire sentence, interpret the word uaing the most specific definition conslatent with the case frame. If the resultant meaning of the case frame lo inconsistent with the Interpretation of the whole sentence, Infor the most llkely consequence of the partlally-build Conceptual Dependency cese frame, and use this consequence in interproting the rest of the aentence.

The process described by rule 5 enables one to interpret the metaphorical uses of words like "lifted" and "bulldozed" in our earller examples. The literal meaning of each word to applied to the object case. (i.e., "barrier"), and the inferred consequence (i.e., destruction of the barrier) to used to interpret the full sentence.

\section{Concluding Aomarka}

There are a multitude of ways to incrementally Improve the language understanding capablittes of a systom. In this paper I discusaed in some detall the process of learning now words. In lesser detall I presented some ideas on how to generallze word meanings and interpret motaphorical uses of Individual words. There are meny more especte to learning languege and understanding metaphors that $I$ have not touched upon. For Inatance, many metaphors transeend individual words and phrases. Their interprotation may require detalled cultural knowledge [10].

In order to place some perspective on project-and-integrate learning method, consider three general learning mechanlama capable of implementing different aspects of incremental lenounge learning.

Learning by exemple. This is perhaps the most general learning strategy. From several exemplars, one can Intersect the common concept by, If necessary, minimally generalizing the meaning of the known part of each example until a common subpart is found by intersection. This common subpart is likely to be the meaning of the unknown section of each exemplar.

Learning by noar-mise analyels. Winston [2] takes full advantage of this technique. It may be usefully applled to a natural language system that can Interactively generate utterances using the words it learned. and later be told whether it used those words correctly, whether it erred sariously, or whether it came close but falled to understand a subtle nuance in meaning.

Learning by contextual expectation. Essentially FOULUP and POLITICs use the mothod of projecting contextual expectations to the 
linguistic element whose meaning is to be Induced. Much more mlleage can be gotten from thls method, especlally if one uses strong syntactic constraints and expectations from other knowledge sources, such as a discourse model, a narrative model, knowledge about who is provlding the information, and why the information is being provided.

\section{Roferences}

1. Lenat, D. AM, Olscovery In Mathemat/cs as Heurlstic Search. Ph.D. Th., Stanford University, 1977.

2. Winston, P. Learning Structural Descriptions from Examples. Ph.D. Th., MIT, 1970.

3. Granger, R. FOUL-UP, A Program that Flgures Out Meanings of Words from Context. IJCAI-77, 1977.

4. Schank, R. C. and Abelson, R. P. Scripts, Goals, Plans and Understanding. Hillside, MJ: Lawrence Eribaum, 1977.

6. Cullingford, R. Script Application Computer Understanding of Newspaper Storles. Ph.D. Th., Yale University, 1877.

6. Carbonell, J. G. POLITICS: Automated Ideological Reasoning. Cognitive Science 2, 1 (1978), 27-51.

7. Carbonell, J. G. Subjective Understanding: Computer Models of Bellef Systems.. Ph.D. Th., Yale University, 1979.

8. Schank, R. C. Conceptual Information Processing. Amsterdam: North-Holland, 1975.

9. Doyle, J. Truth Maintenance Systems for Problem Solving. Master Th., M.I.T., 1978.

10. Lakatt, G. and Johnson, M. Towards an Experimentalist Philosopher: The Case From Literal Metaptor. In preparation for publlcation, 1979. 
